This article was downloaded by: [Concordia University Libraries]

On: 13 August 2013, At: 10:00

Publisher: Taylor \& Francis

Informa Ltd Registered in England and Wales Registered Number: 1072954 Registered

office: Mortimer House, 37-41 Mortimer Street, London W1T 3J H, UK

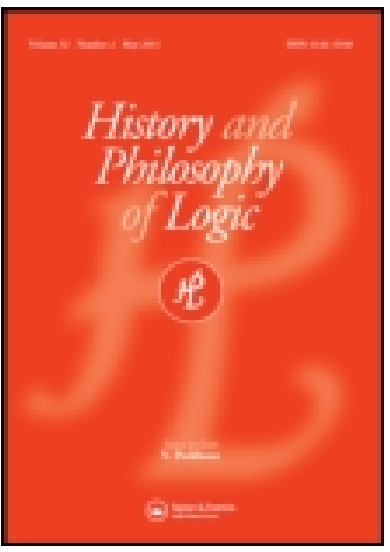

\title{
History and Philosophy of Logic
}

Publication details, including instructions for authors and subscription information:

http:// www. tandfonline.com/loi/thpl20

\section{Frege, Carnap, and Explication: 'Our Concern Here Is to Arrive at a Concept of Number Usable for the Purpose of Science'}

Gregory Lavers $^{a}$

${ }^{a}$ Department of Philosophy, Concordia University, 1455 De

Maisonneuve Blvd., Montreal , QC , Canada , H3G 1M8

Published online: 14 J un 2013.

To cite this article: Gregory Lavers (2013) Frege, Carnap, and Explication: 'Our Concern Here Is to Arrive at a Concept of Number Usable for the Purpose of Science', History and Philosophy of Logic, 34:3, 225-241, DOI: 10.1080/ 01445340.2013.806396

To link to this article: http:// dx. doi.org/ 10.1080/01445340.2013.806396

\section{PLEASE SCROLL DOWN FOR ARTICLE}

Taylor \& Francis makes every effort to ensure the accuracy of all the information (the "Content") contained in the publications on our platform. However, Taylor \& Francis, our agents, and our licensors make no representations or warranties whatsoever as to the accuracy, completeness, or suitability for any purpose of the Content. Any opinions and views expressed in this publication are the opinions and views of the authors, and are not the views of or endorsed by Taylor \& Francis. The accuracy of the Content should not be relied upon and should be independently verified with primary sources of information. Taylor and Francis shall not be liable for any losses, actions, claims, proceedings, demands, costs, expenses, damages, and other liabilities whatsoever or howsoever caused arising directly or indirectly in connection with, in relation to or arising out of the use of the Content.

This article may be used for research, teaching, and private study purposes. Any substantial or systematic reproduction, redistribution, reselling, loan, sub-licensing, systematic supply, or distribution in any form to anyone is expressly forbidden. Terms \& Conditions of access and use can be found at http://www.tandfonline.com/page/termsand-conditions 


\title{
Frege, Carnap, and Explication: 'Our Concern Here Is to Arrive at a Concept of Number Usable for the Purpose of Science'
}

\author{
GREGORY LAVERS \\ Department of Philosophy, Concordia University, 1455 De Maisonneuve Blvd., Montreal, QC, Canada H3G 1M8 \\ greg.lavers@concordia.ca
}

Received 3 March 2012 Accepted 10 November 2012

\begin{abstract}
This paper argues that Carnap both did not view and should not have viewed Frege's project in the foundations of mathematics as misguided metaphysics. The reason for this is that Frege's project was to give an explication of number in a very Carnapian sense - something that was not lost on Carnap. Furthermore, Frege gives pragmatic justification for the basic features of his system, especially where there are ontological considerations. It will be argued that even on the question of the independent existence of abstract objects, Frege and Carnap held remarkably similar views. I close with a discussion of why, despite all this, Frege would not accept the principle of tolerance.
\end{abstract}

\section{Introduction}

I want to explore the relationship between Carnap and Frege on the foundations of mathematics. ${ }^{1}$ It is well known that Frege wished to defend a realist position with respect to the objective existence of mathematical objects. This realist position is often labelled 'platonism' and understood as a metaphysical position one might maintain in the philosophy of mathematics. Carnap, as is also well known, rejected metaphysics. It follows, it seems, that Carnap would clearly reject Frege's views on the foundations of mathematics. This is the view which is expressed quite forcefully in the following passage from Tyler Burge's book on Frege:

I would not take very seriously a reading of Frege as a Carnapian. [...] I think it clear [...] that Frege was trying to provide a rational foundation for mathematics in a way Carnap would have regarded as misguided. Frege saw reason, not practical recommendation, as giving us logical objects (e.g. FA §105). There is nothing remotely akin to Carnap's Principle of Tolerance either in Frege's philosophical pronouncements, or even more emphatically, in his temperament. (Burge 2005, chap. 8, p. 304)

I will not focus too much on Burge's interpretation in particular, although I will address Burge's position in the final section. My primary goal will be to address what I think is a common misconception behind it. In the above quote Burge states that it is obvious, and not worth arguing, that Carnap would see Frege's project in the foundations of mathematics as confused metaphysics. I take it that there are at least many philosophers who would agree with this assessment. However, when we examine what Carnap actually writes about Frege's project, we see that Carnap interprets Frege as attempting to carry out an explication of the concept of number. Far from describing Frege as confused, Carnap describes Frege's

1 Carnap was a student in three of Frege's lecture courses. He recounts his experiences of being taught by Frege in Carnap 1963a. Carnap's lecture notes for Frege's courses are now published as Reck \& Awodey 2004. 
analysis of number as one of the greatest achievements of the late nineteenth to early twentieth centuries. Furthermore, I want to argue that there is good reason to see Carnap as correct in viewing Frege, even as early as Grundlagen, as attempting something very close to a Carnapian explication.

Frege's account of number is guided by very pragmatic considerations (Burge, for instance, explicitly admits as much). I will show that this pragmatism is particularly strong when considering questions of ontology. Of course, Burge is right that there is nothing like the principle of tolerance in Frege's philosophical position. I will close by addressing why this is given the interpretation defended in the early sections of this paper.

In Section 2, I present Carnap's account of explication and explain its relation to what is known as the 'paradox of analysis'. In Section 3, I look at Carnap's actual remarks concerning how he views Frege's project. I show that these remarks clearly support the position that Carnap sees Frege as giving an explication of number. In Section 4, I look at Frege's position put forward in 'Logic in Mathematics' and show its relation to Carnap's account of explication. In Section 5, I argue that Grundlagen is essentially an attempt to give a Carnapian explication of number. I argue that taking this seriously allows one to give a far more charitable interpretation of $\$ \S 55-57$ than the one offered in Dummett 1991b. In the final section, I turn to the question of independent truth of mathematical propositions and the question of pluralism. On the first question I argue that they take the same stance, and for the same reason, while the second question is perhaps the most significant difference between their views.

\section{Carnap and explication}

Carnap's most explicit accounts of explication can be found in Carnap 1947/1956 and Carnap 1950b. Carnap's views on explication are strongly influenced by what is known as the 'paradox of analysis'. The phrase comes from C.H. Langford in a commentary on G.E. Moore's philosophy, but as we will see it was known to Frege (Langford 1942/1968). The paradox of analysis can be explained as follows. Suppose one gives an analysis of some concept $A$ by saying that to be $A$ is to be $B$. If $A$ and $B$ have the same meaning, then the analysis is uninformative. If $A$ and $B$ have different meanings, then the analysis is incorrect. While many might see the paradox of analysis as something of a curiosity, Carnap took it to rule out a certain view on analysis. Given the paradox of analysis, no longer can we view the goal of an analysis to be to uncover what we had meant by some expression all along.

Carnap's answer is that in giving an explication (his term for a philosophical analysis), we replace a poorly understood notion (the explicandum) with a clearly defined analogue (the explicatum). Since we are introducing a new notion, we are not responsible for preserving anything about the explicandum. After mentioning both Langford and Moore, and so clearly with the paradox of analysis in mind, Carnap says the following about explication:

In a problem of explication the datum, [...] viz. the explicandum, is not given in exact terms; if it were, no explication would be necessary. Since the datum is inexact, the problem itself is not stated in exact terms; and yet we are asked to give an exact solution. This is one of the puzzling peculiarities of explication. It follows that, if a solution for a problem of explication is proposed, we cannot decide in an exact way whether it is right or wrong. Strictly speaking, the question whether the solution is right or wrong makes no good sense because there is no clear-cut answer. The question should rather be whether the proposed solution is satisfactory, whether it is more satisfactory than another one, and the like. (Carnap 1950b, §2)

Carnap essentially takes his account of explication to follow from the paradox of analysis. The paradox of analysis shows that the explicatum and the explicandum cannot be the same. 
Therefore, the explicatum must be a newly introduced notion and questions of whether the explicatum is correct must be rejected. The only requirement is that the explicatum be sufficiently similar to the explicandum that it could be used in its place. Carnap 1950b lists four criteria that an explication ought to satisfy:

1. The explicatum is to be similar to the explicandum in such a way that, in most cases in which the explicandum has been so far used, the explicatum can be used; however, close similarity is not required and considerable differences are permitted.

2. The characterization of the explicatum, that is, the rules of its use (for instance, in the form of a definition), is to be given in an exact form, so as to introduce the explicatum into a well-connected system of scientific concepts.

3. The explicatum is to be a fruitful concept, that is, useful for the formulation of many universal statements (empirical laws in the case of a nonlogical concept, logical theorems in the case of a logical concept).

4. The explicatum should be as simple as possible; this means as simple as the more important requirements (1), (2), and (3) permit (Carnap 1950b, §3, original italics).

Notice it is only the first condition that ties the explicatum to the explicandum. Carnap distinguishes between clarifying the explicandum and providing the explicatum. In clarifying the explicandum we attempt to get sufficiently clear on the meaning of a term. By this Carnap means that we could predict which sentences involving the term a user of the language would assent to. At the stage of providing the explicatum, we are not bound in any way by what was identified in the clarification stage beyond the satisfaction of the first of the above desiderata.

Let us now examine some applications of this account in order to understand how it is supposed to work. In Meaning \& Necessity Carnap discusses the proposals of Frege, Russell, and Hilbert and Bernays for how to understand definite descriptions. Frege proposed having a definite description 'the $\Phi$ ' stand for an arbitrarily chosen object when there is no unique $\Phi$. Russell's account is his famous analysis of definite descriptions of 'On Denoting'. Hilbert and Bernays recommend allowing the use of definite descriptions only when there is a provably unique $\Phi$. While there are well-known arguments concerning the correctness of, for instance, Russell's account of definite descriptions, Carnap sees these as beside the point:

The different interpretations of descriptions are not meant as assertions about the meaning of phrases of the form 'the so-and-so' in English, but as proposals for an interpretation and, consequently, for deductive rules, concerning descriptions in symbolic systems. Therefore, there is no theoretical issue of right or wrong between these various conceptions, but only the practical question of the convenience of the different methods. (Carnap 1947/1956, p. 33)

We now have a quite clear picture of Carnap's views on explication. In giving an explication we replace a vague or poorly understood concept with a precise counterpart. There is no question of whether the explicatum is correct, but only practical questions of whether it fulfils the needed role. We are free to accept any set of rules that govern the newly introduced notion. Therefore if we introduce rules governing terms that stand for a new kind of entity, does this mean that sentences involving the newly introduced term are no longer objective and are now to be interpreted as concerning merely linguistic entities? Carnap explicitly 
denies this when discussing his account of propositions in Meaning \& Necessity:

We take as the extension of the sentence its truth-value, and as its intension the proposition expressed by it. This is in accord with the identity conditions for extensions and for intensions stated in the preceding section. Propositions are here regarded as objective, nonmental, extra-linguistic entities. It is shown that this conception is applicable also in the case of false sentences. (Carnap 1947/1956, p. 25)

One is struck by how Fregean this is in two senses. First, of course, Carnap takes the extension of a sentence to be its truth-value and the intension to be the proposition expressed by the sentence. Second, even though it is up to us to fix the truth conditions for identity statements involving propositions (compare Grundlagen §62), they nonetheless concern objective, extralinguistic entities.

This might sound somewhat odd coming from Carnap. How can Carnap claim that statements about propositions concern objective entities? Carnap answers this question in 'Empiricism, Semantics and Ontology'. Here he points out that while it is up to us to formulate the rules governing terms for propositions, the truth conditions for statements about propositions, as determined by those rules, make no mention of us. We do not figure in the truth conditions of statements about propositions:

For example, are propositions mental events (as in Russell's theory)? A look at the rules shows that they are not, because otherwise existential statements would be of the form: 'If the mental state of the person in question fulfils such and such a condition, then there is a $p$ such that ...'. The fact that no references to mental conditions occur in existential statements [...] shows that propositions are not mental entities. (Carnap 1950a, p. 210)

Carnap wishes to introduce a new kind of abstract entity — in this case propositions. He does so by specifying the truth conditions for identity claims involving propositions. He can then claim that statements about propositions are objective and independent of human beings and their mental states. ${ }^{2}$

One might claim that this is, in some sense, a mere manner of speaking. Sure, the objection continues, we can talk of propositions as independent in the sense that we do not figure in their truth conditions, but this somehow falls short of true independence. It is unclear, however, what more could be asked for than this notion of independence. We need to fix the truth conditions for sentences involving propositions. That is, we need to spell out the meanings of the various words, including logical words, that occur in such sentences. Once this is done, whether those truth conditions are satisfied has nothing to do with us. ${ }^{3}$

\section{Carnap on Frege}

We began by considering the assumption that it is somehow obvious that Carnap would have dismissed Frege's project (or at least his method) in the foundations of mathematics as being far too metaphysical. In Burge's words 'Frege was trying to provide a rational foundation for mathematics - in a way Carnap would have regarded as misguided' (Burge 2005, chap. 8, p. 304). I do not know of any passage in Carnap's work where Carnap clearly expresses such a sentiment regarding Frege. Frege is one of the people most often cited

2 Ricketts 1996 claims at the end of the article that by making such claims about propositions (and properties) Carnap has severely blurred the line between semantics and metaphysics. However, if we are clear on what Carnap means by the claim that propositions are objective, no such worry arises.

3 In my Lavers 2009 I take it that this kind of independence does not amount to full independence in some way, I now think that was a mistake. 
by Carnap. Of course many of Carnap's references to Frege are minor technical points or otherwise uninteresting for our present purposes. However, there are also many references to Frege that outline exactly how Carnap understood Frege's project. Far from dismissing Frege as attempting to defend a confused metaphysical position, Carnap interprets Frege as engaged in the task of providing an explication of logical and arithmetical truth. Not only that, but we see Carnap repeatedly offering Frege the highest of praise for his work in this area.

Let us begin by examining a passage that might seem to support the view that Carnap saw Frege as embroiled in metaphysical confusion. In 'Empiricism, Semantics and Ontology' Carnap writes:

Ryle says that the 'Fido'-Fido principle is 'a grotesque theory.' Grotesque or not, Ryle is wrong in calling it a theory. It is rather the practical decision to accept certain frameworks. Maybe Ryle is historically right with respect to those whom he mentions as previous representatives of the principle, viz. John Stuart Mill, Frege, and Russell. If these philosophers regarded the acceptance of a system of entities as a theory, an assertion, they were victims of the same old, metaphysical confusion. But it is certainly wrong to regard my semantical method as involving a belief in the reality of abstract entities, since I reject a thesis of this kind as a metaphysical pseudo-statement. (Carnap 1947/1956, p. 218)

Of course, Carnap does not say here that Ryle is right in his criticism of Frege, Russell, and Mill. Obviously, Carnap is avoiding the question of whether Ryle's criticisms apply to the earlier thinkers mentioned. His main goal is to show that Ryle's criticism does not apply to his own view. The passage might nonetheless suggest that Carnap did in fact think that all three were metaphysically confused. However, once we look in more detail at Carnap's remarks on Frege, we see Carnap does not see Frege as metaphysically confused.

It will be argued in this section that Carnap clearly saw Frege as engaged in the task of giving explications in the sense discussed in the last section. Carnap explicitly describes Frege as attempting to carry out an explication in the sense Carnap has defined. Consider first this passage from Meaning \& Necessity:

It seems that Frege, in introducing his distinction between nominatum and sense, had the intention of making more precise a certain distinction which had been made in various forms in traditional logic. Thus his task was one of explication (in the sense explained in the beginning of $\$ 2$ [in Carnap's sense]). (Carnap 1947/1956, p. 126)

The link between Frege's goals and Carnap's account of explication could not be made more explicit. Here we see that Carnap does not think of Frege's introduction of the notion of sense as a metaphysical confusion - as many contemporary philosophers have. Our main interest here is not, however, with Frege's notion of sense, but with Frege's stance on the foundations of mathematics and mathematical objects in particular. Fortunately, Carnap is no less explicit in making the connection in this case. While Meaning \& Necessity and The Logical Foundations of Probability contained the most detailed discussion of explication, the first discussion of this concept appears in Carnap's 1945 paper 'Two Concepts of Probability'. Here explication is introduced very briefly and then one example of an explication is given, before Carnap turns to the his discussions of probability ${ }_{1}$ and probability ${ }_{2}$. The example given is that of the Frege-Russell definition of the cardinal number three.

Thus, for instance, the definition of the cardinal number three as the class of all triples was meant as an explication; the explicandum was the ordinary meaning of 
the word 'three' as it appears in every-day life and the sciences. (Carnap 1945, p. 513)

There is considerably more evidence that Carnap interpreted Frege as giving an explication of the concept of number. Consider, now, this quote from Introduction to Symbolic Logic and Its Applications:

In the course of constructing our symbolic language systems, it frequently happens that a new precisely-defined concept is introduced in place of one which is familiar but insufficiently precise. Such a new concept is called an explicatum of the old one, and its introduction an explication. (The concept to be explicated is sometimes called the explicandum.) E.g. the concept of L-truth [...] is an explicatum of the concept of logical or necessary truth, which is defined with insufficient exactness despite its frequent occurrence in philosophy and traditional logic. Again, the concept of the inductive cardinal numbers (37c) is an explicatum for the concept of finite number that has been widely used in mathematics, logic and philosophy, but never exactly defined prior to Frege. (Carnap 1958, p. 15)

Here we again see Carnap clearly describing Frege's definition of the finite cardinals as an explication of the concept of finite number. For even more evidence that Carnap understood Frege's definition of number as an explication consider the following quotation from the response to Strawson in the Schilpp volume:

With respect to the numerical words 'one', 'two', etc., ...[f]or thousands of years, many people used these words adequately for all practical purposes, and for several centuries the mathematicians have had a systematically constructed theory involving these words. But even in this case, complete clarity was lacking. Before Frege, nobody was able to give an exact account of the meanings of these words in nonarithmetical terms. By Frege's explication of the numerical words, which I regard as one of the greatest philosophical achievements of the last century, the logical connection between these words and logical particles like 'there is', 'not', 'or', and 'the same as' became completely clear for the first time. Therefore we have to say that in spite of practical skill in usage, people in general, and even mathematicians before Frege, were not completely clear about the meaning of numerical words. (Carnap 1963b, p. 935, my italics)

Here Carnap goes so far as to employ the term 'explication' in describing Frege's definition of number. I take it that it can now no longer be doubted that Carnap understood Frege's definition of number as a (Carnapian) explication of the concept of number.

There is now an objection that one is likely to raise. One might think it is clear that Carnap interpreted Frege as offering a Carnapian explication of number, but insist this is an instance of Carnap being overly charitable to Frege. That is, in these passages, Carnap ignores Frege's most metaphysical sounding pronouncements, and gives the best possible (in Carnap's view) interpretation of the rest. According to this objection then there is much in Frege that Carnap would have to dismiss as metaphysical nonsense that Carnap simply ignores in understanding Frege as giving an explication. Much of the answer to this objection will need to be postponed until later sections (after Frege's own views have been discussed in more detail). I would, however, like to sketch my response before closing this section.

The response is simple: Carnap would agree with all of Frege's most metaphysical sounding pronouncements. Many would assume that Carnap would have to reject such claims as: 'numbers are self-subsistent objects'. Let us interpret this as the claim that numbers are objects that are independent of human beings, their practices (including linguistic practices) and their mental states. We saw in the previous section that Carnap took propositions to 
be objective abstract objects that are independent of human beings and their mental states. The reason for this was that we do not figure in the truth conditions for statements involving propositions. For exactly the same reason, Carnap would say that numbers are abstract objects that are independent of human beings, their practices, and mental states.

\section{Frege's 1914 'Logic in Mathematics' view}

In the previous section it was argued that Carnap saw Frege as engaged in the project of carrying out an explication of arithmetical terms. In this section I want to argue that Carnap's assessment of Frege is largely right. ${ }^{4}$ I will examine Frege's explicit remarks as presented in his 1914 paper 'Logic in Mathematics' on how the construction of a mathematical system is supposed to proceed. ${ }^{5}$ In the next section, I will discuss Grundlagen and its relation to Carnapian explication.

Frege begins his examination of the role of analyses by asking the question 'how does one judge whether a logical analysis is correct?' (Frege 1914/1979, p. 209). His answer is that a definition seems to be playing a double role. A definition says of a simple sign that it has the same meaning as a complex expression (whose constituents are assumed understood). This can be seen, on the one hand, as a self-evident assertion concerning the long established use of the simple expression. In this case the definition ought to be seen as an axiom. On the other hand, however, this equivalence is just what the definition was meant to stipulate. Definitions cannot simultaneously report an existing synonymy and stipulate that an equivalence in meaning is to hold. This problem of the double role of definitions is none other than the paradox of analysis that we saw Carnap responding to above. In response to this problem Frege makes a distinction.

We have therefore to distinguish two quite different cases:

(1) We construct a sense out of its constituents and introduce an entirely new sign to express this sense. This may be called a 'constructive definition', but we prefer to call it a 'definition' tout court.

(2) We have a simple sign with a long established use. We believe that we can give a logical analysis of its sense, obtaining a complex expression which in our opinion has the same sense. (Frege 1914/1979, p. 210)

Thus we have two fundamentally different projects. Definition confers meaning on a new sign. Analysis is the identification of the sense that an long established sign is taken to have. So far neither of these may sound very similar to what Carnap calls explication. Sure Carnap's account of explication involves stipulation, but Frege's allowing arbitrary definitions of new terms does not amount to anything like accepting a Carnapian account of explication. However, both definition and analysis play a role in a larger project - that of the construction of a system. Frege's remarks on the construction of a system make it clear that he is speaking of something similar to a Carnapian explication. As we saw above, Carnap distinguishes between clarifying the explicandum and providing the explicatum. Analysis for Frege, like the clarification of the explicandum, is a merely preparatory task:

The effect of the logical analysis of which we spoke will then be precisely this to articulate the sense clearly. Work of this kind is very useful; it does not, however, form part of the construction of the system, but must take place beforehand. Before

\footnotetext{
4 Michael Beaney has pointed out the similarities between Carnap on explication and Frege's 1914 account. See Beaney 1996 and Beaney 2004.

5 'Logic in Mathematics' was a set of notes for a course for which Carnap was a student (see Reck \& Awodey 2004). Carnap, however, did not formulate his account of explication until the mid 1940s. Therefore, it is unlikely that Carnap derived his account of explication directly from this course.
} 
the work of construction is begun, the building stones have to be carefully prepared so as to be usable; i.e. the words, signs, expressions, which are to be used, must have a clear sense, so far as a sense is not to be conferred on them in the system itself by means of a constructive definition. (Frege 1914/1979, p. 211)

After the preparatory task of analysis is done we introduce a new term whose constructive definition is arbitrary. The fact that the old and new term coincide is a mere matter of convenience:

If we have managed in this way to construct a system of mathematics without the need for the sign $A$ [a sign with an existing sense], we can leave the matter there; there is no need at all to answer the question concerning the sense in which this sign had been used earlier. In this way we court no objections. However it may be felt expedient to use the sign $A$ instead of the $\operatorname{sign} B$ [the newly introduced sign]. But if we do this, we must treat it as an entirely new sign which has no sense prior to the definition. We must explain that the sense in which this sign was used before the new system was constructed is no longer of any concern to us, that its sense is to be understood purely from the constructive definitions that we have given. (Frege $1914 / 1979$, p. 211)

We begin by giving an analysis of the term we wish to provide a systematic account of. In doing so we identify the various properties we take it to have. This parallels what Carnap calls clarifying the explicandum. We then construct a system, using the same term for convenience. However, the meaning of the new term is conferred on it by definition and ties to the older notion are severed. The old term, that is, has been replaced by one whose meaning is entirely determined by constructive definition. Carnap would of course call this providing the explicatum. ${ }^{6}$

\section{Explication in Grundlagen}

It should be clear that Frege's 1914 account of the construction of a system of mathematics is very similar to what Carnap called an explication. I want now to claim that even as early as 1884 , Frege was engaged in giving an explication of number in very much this sense. That is not to say Frege had the general views of his 1914 article worked out by 1884 . Beaney 1996 shows that Frege's 1914 article came after several unsuccessful attempts at answering the paradox of analysis. What I want to claim is that the definition of number in the Grundlagen is an instance of the type of project described in the 1914 paper. I am not alone in viewing the definition of number in Grundlagen as essentially a Carnapian explication of number. Dummett has argued that it is hard to view the definitions presented there as something other than a Carnapian explication:

Whatever it is that we ordinarily mean to be referring to when we speak, say, of the number of students presently at the University of Bologna, it is assuredly not the class of concepts $\mathrm{G}$ such that there are just as many Gs as there are students at the University of Bologna. And since all the subsequent definitions depend, in the sense stated, upon the definition $(\mathrm{N})$ of the cardinality operator, the same must be said of them. It thus appears that, at best, the definition $(\mathrm{N})$ is an explication in the sense of Carnap. (Dummett 1991a, p. 33)

\footnotetext{
${ }^{6}$ Frege would place more importance on preserving what was identified in the process of analysis than Carnap's explicit account requires. However, as I argue in Lavers 2008, Carnap when explicating mathematical truth is concerned to preserve the properties we standardly take it to have.
} 
Later in this section, I will argue that a problem which Dummett sees with Frege's analysis of number is, in fact, not a problem at all if Frege is interpreted as giving a Carnapian explication of number. The problem in question is Frege's view that numbers are objects. Dummett himself sees Frege as giving a Carnapian explication of number. Therefore the question that will be addressed in the discussion of Dummett is not whether Frege was involved in giving a Carnapian explication of number in Grundlagen, but how this should affect our understanding of his claim that numbers are objects.

Let us first examine what Frege says about standards of satisfactory definitions in Grundlagen. We will see this supports the interpretation of Frege as engaged in Carnapian explication. In the Grundlagen, Frege seeks to define the individual numbers, the successor relation, the general concept of number, and finally the concept of finite number. At certain places in the work, Frege describes what he understands as the criterion of success of a definition. On page ix of the introduction, Frege writes: 'Even I agree that definitions prove their worth by being fruitful. ${ }^{7}$ This thought is expanded upon in $§ 70$ :

Definitions show their worth by proving fruitful. [...] Let us try, therefore, whether we can derive from our definition of the Number which belongs to the concept $F$ any of the well known properties of number. (Frege 1884/1980, §70)

A definition of number is successful if from it we can derive the well-known properties of number. That is to say, a systematic account of number, usable for the purpose of science, should at least allow one to demonstrate all that could be demonstrated in a pre-systematic treatment of number. Once Frege offers his own definition, he shows that this definition of numbers as extensions allows one to derive the important properties of number. Just prior to this, Frege says something which clearly suggests that he does not take his definition of numbers as extensions to have identified what we have meant by number all along:

That this definition is correct will perhaps be hardly evident at first. For do we not think of the extensions of concepts as something quite different from numbers? [...] [I]t is not usual to speak of a Number as wider or less wide than the extension of a concept; but neither is there anything to prevent us from speaking in this way, if such a case should ever occur. (Frege 1884/1980, §69)

Therefore we can say that, on Frege's view, for a definition of number to be successful it need not identify what we have always meant by number (it can ascribe new properties to number), but the well-known properties of number must be recoverable from the definition.

With this as Frege's criterion of a successful definition, we can understand his criticisms of various rival definitions of number as simply an application of the same standard:

When Stricker, for instance, calls our ideas of number motor phenomena and makes them dependent on muscular sensations, no mathematician can recognize his numbers in such stuff or knows what to make of such propositions. (Frege $1884 / 1980$, p. v)

Why does Stricker's definition fail? Because identifying numbers with motor phenomena will not allow us to recover the recognized properties of number. It is not so much that numbers are not motor phenomena as that such an identification will make for a hopelessly unfruitful definition of number.

7 The 'Even I' here is a reference to Frege's strict standards of proof. 
Likewise, consider this passage where Frege is quite sarcastically attacking psychological accounts of number:

If the number two were an idea, then it would have straight away to be private to me only. Another man's idea is, ex vi termini, another idea. We should then have it might be many millions of twos on our hands. We should have to speak of my two and your two, of one two and of all twos. If we accept unconscious ideas, we should have unconscious twos among them, which would return subsequently to consciousness. As new generations of children grew up, new generations of twos would continually be born, and in the course of millennia these might evolve, for all we could tell, to such a pitch that two of them should make five. Yet in spite of all of this, it would still be doubtful whether there existed the infinite number of numbers that we ordinarily suppose. $10^{10}$, perhaps, might be only an empty symbol, and there might exist no idea at all, in any being whatever, to answer to that name. (Frege 1884/1980, §27, my italics)

There are two ways to interpret this passage. The first is as a reductio of the view that numbers are ideas. That is, Frege's goal here is to argue that the view that numbers are ideas is false. This interpretation assumes that Frege takes it to be a desideratum of a definition of number that it identify the numbers with what they really are (or, at least, have always been). However, as we have seen, with respect to his own definition of number Frege does not hold this position. On this interpretation then, Frege applies different standards to his own definitions and to others.

The other interpretation, strongly suggested by what has already been said, is that Frege is arguing that identifying numbers with ideas will fail as an explication of number - we cannot recover their familiar properties. We cannot, for instance, show that there are an infinity of numbers. Frege's insistence that numbers are objective and extra-mental, on this interpretation, amounts to the observation that the identification of numbers with something subjective or mental will result in an unsatisfactory definition of number - a concept not usable for the purpose of science.

As mentioned above, I want to defend the position that a certain aspect of Frege's thinking, which Dummett views as extremely problematic becomes less so when it is taken seriously that Frege is engaged in a Carnapian explication of number. The aspect of Frege's thinking that I have in mind here is Frege's view that numbers are self-subsistent objects. Dummett $1991 b$ describes sections $\$ \$ 55-57$ of the Grundlagen, which Dummett sees as an extended argument to the effect that numbers are objects, as containing some of the worst arguments Frege ever presented. Concerning Frege's view that numbers are self-subsistent objects, Dummett writes:

His view of the status of numbers, ontological and epistemological, proved to be catastrophically wrong; for the last nineteen years of his life, he himself acknowledged it to have been wrong, and regarded that as bringing with it the collapse of his entire philosophy of arithmetic. (Dummett 1991b, p. 292)

On Dummett's interpretation, Frege presents, in $\$ 55$, three definitions which are meant to pursue the 'adjectival strategy'. The definitions given there are as follows:

The number 0 belongs to a concept, if the proposition that $a$ does not fall under that concept is true universally, whatever $a$ may be.

The number 1 belongs to a concept $F$, if the proposition that $a$ does not fall under $F$ is not true universally, whatever $a$ may be, and if from the propositions that ' $a$ falls under $F$ ' and ' $b$ falls under $F$ ' it follows universally that $a$ and $b$ are the same. 
The number $(n+1)$ belongs to the concept $F$, if there is an object $a$ falling under $F$ and such that the number $n$ belongs to the concept 'Falling under $F$, but not $a$ '.

Frege then goes on to criticize these definitions in $\$ 56$, which, Dummett maintains, contains the heart of the argument that numbers are objects. Dummett describes this section as follows:

Frege aimed to show all three definitions erroneous, and thereby to prove a purely adjectival strategy unfeasible, because numbers have to be recognized as being objects. In this he utterly failed: in fact $\$ 56$ may be stigmatized as the weakest in the whole of Grundlagen. The arguments lack all cogency: they more resemble sleight of hand. (Dummett 1991b, p. 105)

On Dummett's view then $§ \S 55-57$ contain an extended, and incredibly poor, argument to the effect that numbers are objects. I will present four reasons why Dummett's reading of these sections should be rejected. First, it is obviously a very uncharitable reading of these sections. Second, the adjectival reading of the definitions given in $\$ 55$ is not suggested by the text. ${ }^{8}$ Third, the Caesar objection of $\$ 56$ is not just unexpected, but makes no sense on Dummett's interpretation. And lastly, the adjectival use of number words is not mentioned explicitly until $\$ 57$.

There is not much that needs to be said about the first reason for why Dummett's interpretation is mistaken. It needs only be mentioned that if there is a more charitable interpretation available, it is at least prima facie more plausible. Let us move on then to the second reason. When looking at the above definitions, we see that they do not appear to be adjectival. They explicitly involve the definite article before the numerical term on the LHS. For instance the first begins with the phrase 'the number 0 belongs to a concept'. Dummett describes this as Frege's 'question begging jargon'. Here Dummett assumes that the definitions are meant to be adjectival and then sees Frege's language as obviously question begging. I want to suggest that there is nothing about $\S \S 55-56$ to suggest that Frege is pursuing an adjectival strategy. ${ }^{9}$ If we do not read an adjectival strategy into the definitions of number presented here, then the definitions of $\$ 55$ are a first attempt at defining numerical terms (terms for numbers as objects). Frege's arguments against these definitions are not then part of an argument that numbers are objects.

Dummett understands Frege as attempting to carry out an adjectival definition of number by defining numbers as exponents to quantifiers. Dummett translates the first of these definitions into logical notation as follows: ${ }^{10}$

$$
\left(\exists_{0} x\right) F x \Longleftrightarrow \sim(\exists x) F x
$$

This symbolic presentation of the definition is, of course, found nowhere in Frege's text. By translating them this way, Dummett is expressing what he takes Frege's understanding of the logical form of these definitions to be. I suggest that a more faithful translation of Frege's words into logical notation would be the following:

$$
N F=0 \Longleftrightarrow \sim(\exists x) F x
$$

8 This point is of particular importance given that many commentators now assume Dummett's interpretation of $\$ \S 55-56$.

9 Wray 1995 argues against Dummett's interpretation of $\$ 56$. Although I agree with some of Wray's points, he does not reject Dummett's supposition that the definitions of $\$ 55$ are meant to be adjectival.

10 I will focus on the first definition, but, as should be clear, exactly analogous points could be made regarding the remaining two definitions. 
On this interpretation then, Frege is clearly not proposing adjectival definitions in $\S 55 .{ }^{11}$ Here the numeral zero clearly appears in the position of a name. Let us now look the German original:

einem Begriffe kommt die Zahl 0 zu, wenn allgemein, was auch a sei, der Satz gilt, dass a nicht unter diesen Begriff falle. (Frege 1884, §55)

We see that it clearly involves the phrase 'die Zahl 0'. Dummett has to interpret Frege's use of the definite article as some combination of major dishonesty and major oversight. On the interpretation where Frege is not pursuing the adjectival strategy in $§ 55$, no such assumption needs be made. Furthermore, compare this formulation with Frege's formulation of the LHS of Hume's principle:

die Zahl, welche dem Begriffe F zukommt, ist dieselbe, welche dem Begriffe G zukommt. (Frege 1884, §62)

This is standardly translated into logical notation as:

$$
N F=N G .
$$

Given the very similar language used to formulate the LHS of Hume's principle and the LHS of the definitions of $\S 55$, if Hume's principle is to be seen as an attempted definition of numerical terms, so should the definitions of $\$ 55 .^{12}$

If the definitions of $\$ 55$ are not adjectival definitions of number, then the criticisms of those definitions in $\$ 56$ are not arguments to the effect that numbers are objects. Dummett charges that Frege repeatedly begs the question in this section. In fact, as Dummett reads him, Frege is so obviously begging the question, that it is incredible that Frege himself did not realize this. However, if the definitions of $\$ 55$ were meant as a definition of numerical terms, then these problems are avoided. This now brings us to the third of the points I wanted to make against Dummett's interpretation. This point concerns Dummett's interpretation of the Caesar objection of $\$ 56$. Concerning the Caesar objection against the definitions in $\S 55$, Dummett says no more than that a first time reader cannot see the objection as making much sense. The reason for this appears to be that, given his interpretation, Dummett can say nothing more about it. If $\S 55$ presents adjectival definitions of number — something along the lines of numbers as exponents to quantifiers - then why on Earth would Frege consider whether there are Julius Caesar Fs for some concept F? It is not only the first time reader that is at a loss to understand this, there is absolutely no reason to consider this possibility if numbers are exponents to quantifiers. On the other hand, according to the interpretation of the present paper, 'Julius Caesar' is a valid substitution instance for ' $x$ ' in

11 I use $N F=0$ here for clarity and because of the fact that $N F$ is quite standardly taken to be a term for an object. However, I do not think this is quite right either. When Frege says 'The number $n$ belongs to a concept $F$ ' he takes this to have the form ' $x$ belongs to $\phi$ ', which we might write $B(x, \phi)$. ' $x$ ' here is a variable that ranges over objects, while ' $\phi$ ' is a variable that ranges over first level concepts. Therefore the actual form of the first definition is $B(0, F) \Longleftrightarrow \sim(\exists x) F x$. The reason the form $N F=x$ cannot be right is that in $\S 56$ Frege complains that if $a$ and $b$ both belong to the concept $F$, we cannot use the definition to prove $a=b$. But $a=b$ clearly does follow from $(N F=a) \&(N F=b)$ (but not from $B(a, F) \& B(b, F)$ ).

I point out below the similarity of the language in $\$ 55$ and $\$ 62$. To say, using the $B$ notation explained here, that the number that belongs to the concept $F$ is the same as the number that belongs to the concept $G$ if and only if $F$ and $G$ are equinumerous, one would write:

$$
(\exists x)(\exists y)(B(x, F) \& B(y, G) \& x=y) \Longleftrightarrow F \approx G .
$$

While I think this $B$ notation is the correct representation of what Frege has in mind, I will stick to a more standard notation in the main text of this article.

12 What I mean to point out here is the similarity of the forms 'einem Begriffe kommt die Zahl 0 zu' and 'die Zahl, welche dem Begriffe F zukommt'. If we interpret one as making reference to a number (as an object), then it seems the other must as well. Of course, 'ist dieselbe' does not occur in the definitions of $\$ 55$. See the previous footnote. 
the formula ' $N F=x$ '. What the Caesar objection is meant to show is that the definitions of $\S 55$ do not fix the extension of the concept number. Of course this is exactly what Frege himself says after mentioning Caesar. ${ }^{13}$

So far I have argued that neither $\$ 55$ nor $\$ 56$ concern the adjectival definition of number. This brings us to the final point in our discussion of Dummett on $\S \S 55-57$ : adjectival formulations are not explicitly mentioned until §57. It is only in this section that Frege considers such formulations as 'Jupiter has four moons'. Frege here points out that the fundamental thought of $\S 46$ does not force us to treat numbers as properties of concepts. These brief remarks in $\$ 57$ are the only sentences in these sections that explicitly concern treating numbers adjectivally. There is not an extended argument that runs from $\S 55$ to $\$ 57$ to the effect that numerical claims must be understood as concerning objects. In fact, the entirety of Frege's 'argument' that numbers are objects is contained in the following two sentences:

I have already drawn attention above to the fact that we speak of 'the number 1 ,, where the definite article serves to class it as an object. In arithmetic this selfsubsistence comes out at every turn, as for example in the identity $1+1=2$. (Frege $1884 / 1980, \$ 57$, my emphasis)

There are just two reasons given for why Frege seeks to define numbers as objects. The first is the use of the definite article and the second is that numerical identities are ubiquitous in arithmetic. Of course the second of these presupposes Frege's view that equations are best viewed as identities. ${ }^{14}$ Dummett sees Frege as trying to definitively establish that numbers must be defined as objects, and Dummett sees these arguments as incredibly poor. Yet if $§ 55$ and $\$ 56$ do not concern adjectival definitions of number, and the only reasons motivating a definition of numbers as objects are the two presented in the quote above, then Frege is clearly not trying to show that numbers must be defined as objects. A central claim of the present paper is that Frege is engaged in something like a Carnapian explication of number. He is not trying to definitively establish that numbers are objects, but takes himself as free to do so if such a definition could play the required role. Immediately after the previous quote, Frege continues with the line that is the secondary title of this paper:

Now our concern here is to arrive at a concept of number usable for the purpose of science; we should not therefore be deterred by the fact that in the language of everyday life number appears also in attributive constructions. That can always be got round. (Frege 1884/1980, §57, my emphasis)

On the present interpretation Frege does not require any philosophical argument to the effect that numbers are objects. Frege seeks from the outset to define numbers as objects, and definitions prove their worth by being fruitful. If from the definition he provides we are able to recover the familiar properties of number, then that definition is a success by the standards of the Grundlagen.

\section{Frege, Carnap, tolerance, and independence}

Carnap is perhaps best known for the position he defends in 'Empiricism, Semantics and Ontology'. Here Carnap defends the view that meaningful questions concerning the existence of objects can be posed only from within a framework. If we wish to introduce a kind of object, we need to define the appropriate framework. Once this is done, we can

13 I would, of course argue that all of the objections presented in $\$ 56$ make far more sense on the assumption that the definitions of $\$ 55$ are not adjectival.

14 Frege does give an argument for why we should view equations as identities in Frege 1914/1979, pp. 223. 
show that objects of this kind exist relative to the framework which we have defined. Many have interpreted Carnap here as defending a view that we can define objects into existence. Frege, on the other hand, is well known to have maintained that we cannot create objects with definitions. There may, therefore, seem to be a conflict between Frege and Carnap on this matter. I will argue in this section that once we distinguish between definitions and basic laws, this apparent conflict vanishes. That said, there is a difference between Frege and Carnap on the question of pluralism. Frege gave pragmatic justification for the basic principles of his system, especially when there were ontological implications. Despite this, he was not a pluralist, because he believed that anyone who tried to carry out the same project - that of giving a systematic account of arithmetic — would have to make essentially all the same pragmatic choices. I will argue that it is rejecting this supposition on Frege's part that constitutes the major point of disagreement between Frege and Carnap on the foundations of mathematics.

Let us begin by looking at Frege's claim that we cannot create objects with definition:

Now suppose one defines, for instance, the number zero, by saying: it is something which yields one when added to one. In so doing one has defined a concept, by specifying what property an object must have in order to fall under the concept. But this property is not a property of the concept defined. People frequently seem to fancy that by the definition something has been created that yields one when added to one. A great delusion! The concept defined does not possess this property, nor is the definition any guarantee that the concept is realized - a matter requiring separate investigation. Only when we have proved that there exists at least and at most one object with the required property are we in a position to invest this object with the proper name 'zero'. To create zero is consequently impossible. (Frege 1893/1967, pp. 11-12)

In this passage, Frege is making a simple logical point. This logical point is consistent, of course, with Frege's realism, but is not itself an expression of this realist attitude. The logical point is that the concept 'something which yields one when added to one' does not itself introduce an object. It is only once we can prove that there is one and only one object that falls under this concept that we are free to introduce a proper name that stands for an object. Frege is not here talking about basic laws, and claiming that we cannot lay down basic laws that introduce objects. As we will see, Frege does think we can accept basic laws that introduce objects. There is then nothing about this quote that implies a point of disagreement between Carnap and Frege. Presumably Carnap would fully accept the logical point made here.

When Carnap says that after one has accepted the framework of arithmetic it is trivial to demonstrate the existence of number, he is not making the error that Frege is criticizing above. The principles that define a framework are basic truths. If we want to compare Carnap and Frege's position on this matter we must look not to Frege's remarks on definition but to his discussion of basic laws. Of course, Frege maintains that basic laws cannot be justified. We can justify a non-basic logical law by reducing it to something more basic, but there is strictly nothing that could serve as a justification of a basic logical law. Frege, however, often gives pragmatic arguments in favor of his basic laws. Never is this more apparent than when he is defending aspects of his system with ontological implications. For instance, here is what he says about the introduction of truth-values as objects in the Grundgesetze:

How much simpler and sharper everything becomes by the introduction of truthvalues, only detailed acquaintance with this book can show. These advantages alone put a great weight in the balance in favor of my own conception, which indeed may seem strange at first sight. (Frege 1893/1967, p. 7) 
Similarly when he introduces courses of values he writes 'The introduction of courses-ofvalues of functions is a vital advance, thanks to which we gain far greater flexibility' (Frege $1893 / 1967$, p. 6).

I began this paper with a quote from Burge to the effect that Frege is obviously non-Carnapian and engaged in a project that Carnap would clearly dismiss as confused metaphysics. We saw above that Carnap certainly did not dismiss Frege's project as misguided metaphysics. Furthermore, we have seen that there is much in Frege to support Carnap's interpretation that Frege is engaged in a project resembling Carnapian explication. Finally, we have just seen that Frege provides pragmatic arguments in favor of the basic laws of his system. I want to turn now to Burge's interpretation and what he regards as the principal difference between Frege and Carnap. This difference concerns the objectivity and independence of arithmetical truths. Burge agrees that Frege provides pragmatic reasons for accepting his laws, but contends that they are nonetheless objective and independent in a sense that Carnap would presumably deny:

I hope that it is clear that by calling epistemic considerations 'pragmatic' I am in no way implying that Frege thought them any less able to put us on to truths about a reality independent of our practice. (Burge 2005, chap. 9, p. 341)

I will argue the independence of arithmetical truths is not something that separates Frege and Carnap's position. In fact, they seem to have the same view concerning what makes the truth of a proposition independent of our practices. Of course, Frege is not a pluralist and Carnap is, but this, I contend, is a question that is distinct from the question of independence.

It is clear that Frege considered the truth of arithmetical propositions to be independent of our practices and mental states. Consider for example this quote from the Grundlagen:

For number is no whit more an object of psychology or of mental processes than, let us say, the North Sea is. The objectivity of the North Sea is not affected by the fact that it is an arbitrary choice which part of all the water on the earth's surface we mark off and elect to call the 'North Sea'. This is no reason for deciding to investigate the North Sea by psychological methods. In the same way number, too, is something objective. If we say 'the North Sea is 10,000 square miles in extent' then neither by 'North Sea' nor by ' 10,000 ' do we refer to the state of or process in our minds: on the contrary, we assert something objective, which is independent of our ideas and everything of the sort. (Frege 1884/1980, §26)

By making a quite arbitrary decision that a certain portion of the surface of the Earth will be called the 'North Sea', we thereby fix the truth conditions for sentences that contain the name 'the North Sea'. That a certain mental event (the decision) was necessary for those truth conditions to be fixed the way they were, does not affect the objectivity of propositions about the North Sea. The reason for this is that whether those truth conditions obtain has nothing to do with any of our mental states. That is, we do not figure in the truth conditions for these propositions. We saw above that in discussion the objectivity of claims about propositions, Carnap maintained that they are objective in that we do not figure in the truth conditions for claims about propositions. Therefore not only is it not the case that Frege did but Carnap did not maintain the independent existence of abstract objects, but both Frege and Carnap held the same standards for when something exists independently of our practices and our mental states.

It may now be worthwhile to consider an objection. One might claim that, for Carnap, propositions of arithmetic are independent of us in the sense that we do not figure in their truth conditions, but they are still dependent on us in the sense that they are true by convention. However, in his reply to Strawson in the Schilpp volume, Carnap maintains that he thinks 
talk of conventions is unhelpful. In fact he straightforwardly denies that sentences such as 'all black dogs are black' are true by convention:

Once the meanings of the individual words in a sentence of this form are given (which may be regarded as a matter of convention), then it is no longer a matter of convention or of arbitrary choice whether to regard the sentence as true; the truth of such a sentence is determined by the logical relations holding between the given meanings. (Carnap 1963c, p. 916)

We have seen that Frege is interested in giving what is essentially a Carnapian explication of number. Moreover, we have seen that Frege is clearly guided by pragmatic considerations when introducing such things as courses of values or truth-values. Why then did Frege not hold something like Carnap's principle of tolerance? The answer is that Frege thought that anyone who tried to carry out the same task - to give a scientific account of arithmetic would have to make essentially the same pragmatic choices. For example, anyone trying to give a systematic account of number would see the need to introduce truth values as objects. But even with regard to the truth of the system as a whole, Frege is quite pragmatic:

It is prima facie improbable that such a structure could be erected on a base that is uncertain or defective. Anyone who holds other convictions has only to try to erect a similar structure upon them, and I think he will perceive that it does not work, or at least does not work so well. As a refutation of this I can only recognize someone's actually demonstrating either that a better, more durable edifice can be erected upon other fundamental convictions, or else that my principles lead to manifestly false conclusions. (Frege 1893/1967, p. 25)

Notice Frege says he will recognize his system as faulty only if it either leads to false conclusions or a clearly superior one could be constructed. Frege famously expresses some reservations about his Basic Law V in Grundgesetze, but he was nonetheless confident (before the letter from Russell) that neither of these possibilities would arise. Frege thought, perhaps somewhat dogmatically, that any attempt to achieve the goal of a truly systematic account of arithmetic would converge on all essential features. Carnap, from his perspective many years later, could see the possibility of an account of arithmetic with and without truth values as objects for instance. Carnap would disagree with Frege's view that all truly systematic treatments of arithmetic will converge in their essential features.

Consider the claim that numbers are objects. Carnap would see introducing the numbers as objects as one possible way to give a systematic account of arithmetic. However, Carnap might also see introducing an axiom of infinity and then associating numbers with second order properties as another way to accomplish the same goal. The decision between these options Carnap might treat as arbitrary. But once a decision is taken here this does not make the propositions of the chosen system subjective, or dependent on us, or merely linguistic. It is not the objectivity of arithmetic that separated Frege and Carnap. What separated them was Frege's belief that anyone who attempted the same goal — providing a systematic account of arithmetic - would have to make essentially the same pragmatic choices as he did. Carnap, however, would understand Frege as holding this view because of the lack, at the time, of any alternative equally systematic treatment of number. ${ }^{15}$ Carnap would, that is, see Frege's fault as being too far ahead for his time, and not as being metaphysically misguided.

15 Of course, Frege was aware of alternative systems of logic such as Boole's and Peano's, but Frege clearly saw them as unable to accomplish the goal of providing a scientific account of arithmetic. 


\section{Acknowledgements}

Thanks to Steve Bland, Mauro Corneli, William Demopoulos, and David DeVidi for discussions and comments that led to improvements in the paper. Thanks also to members of the various audiences to which I presented these ideas.

\section{References}

Beaney, M. 1996. Frege: Making Sense, London: Duckworth.

Beaney, M. 2004. 'Carnap's conception of explication: from Frege to Husserl?', in S. Awodey and C. Klein, eds., Carnap Brought Home: The View from Jena, Chicago, IL: Open Court, pp. 117-50.

Burge, T. 2005. Truth Thought Reason: Essays on Frege, Oxford: Oxford University Press.

Carnap, R. 1945. 'The two concepts of probability: the problem of probability', Philosophy and Phenomenological Research, 5(4), 513-32.

Carnap, R. 1947/1956. Meaning and Necessity: A Study in Semantics and Modal Logic, 2nd ed., Chicago: University of Chicago Press.

Carnap, R. 1950a. 'Empiricism, semantics and ontology', Revue International de Philosophie, 4, 20-40 (Reprinted in Meaning and Necessity: A Study in Semantics and Modal Logic, 2nd ed., Chicago: University of Chicago Press, 1956).

Carnap, R. 1950b. Logical Foundations of Probability, Chicago: University of Chicago Press.

Carnap, R. 1958. Introduction to Symbolic Logic and Its Applications, New York: Dover (revised english translation ed.).

Carnap, R. 1963a. 'Intellectual autobiography', in P.A. Schilpp, ed., The Philosophy of Rudolf Carnap, vol. XI, Library of Living Philosophers, La Salle, IL: Open Court, pp. 927-32.

Carnap, R. 1963b. 'P.F. Strawson on linguistic naturalism', in P.A. Schilpp, ed., The Philosophy of Rudolf Carnap, vol. XI, Library of Living Philosophers, La Salle, IL: Open Court, pp. 933-40.

Carnap, R. 1963c. 'W.V. Quine on logical truth', in P.A. Schilpp, ed., The Philosophy of Rudolf Carnap, vol. XI, Library of Living Philosophers, La Salle, IL: Open Court, pp. 915-22.

Dummett, M. 1991a. 'Frege and the paradox of analysis', in M. Dummett, ed., Frege and Other Philosophers, Oxford: Oxford University Press, pp. 17-52.

Dummett, M. 1991b. Frege: Philosophy of Mathematics, Cambridge, MA: Harvard University Press.

Frege, G. 1884. Grundlagen der Arithmetik. Eine logisch mathematische Untersuchung ü̈er den Begriff der Zahl, Breslau: Verlag von Wilhem Koebner.

Frege, G. 1884/1980. The Foundations of Arithmetic, second revised ed., Evanston, IL: Northwstern University Press.

Frege, G. 1893/1967. The Basic Laws of Arithmetic: Exposition of the System, edited and translated by Montgomery Furth, Berkeley: University of California Press.

Frege, G. 1914/1979. 'Logic in mathematics', in F.K. Hans Hermes, Freidrich Kambartel, eds., Poshumous Writings, Oxford: Basil Blackwell, pp. 203-50.

Langford, C.H. 1942/1968. 'The notion of analysis in Moore's philosophy', in P.A. Schilpp, ed., The Philosophy of G. E. Moore, vol. i, La Salle, IL: Open Court, pp. 321-42.

Lavers, G. 2008. 'Carnap, formalism, and informal rigour', Philosophia Mathematica, 16(1), 4-24.

Lavers, G. 2009. 'Benacerraf's dilemma and informal mathematics', Review of Symbolic Logic, 2(4), 769-85.

Reck, E.H. and Awodey, S., eds. 2004. Frege's Lectures on Logic: Carnap's Student Notes, 1910-1914, Chicago, IL: Open Court.

Ricketts, T. 1996. 'Carnap: from logical syntax to semantics', in R. Giere and A.W. Richardson, eds., The Origins of Logical Empiricism, vol. XVI, Minnesota Studies in the Philosophy of Science, Minneapolis: University of Minnesota Press, pp. 231-50.

Wray, K.B. 1995. 'Reinterpreting section 56 of Frege's The Foundations of Arithmetic', Auslegung: A Journal of Philosophy, 20(2), 76-82. 